\title{
PEIRCE, JAKOBSON Y LA ESENCIA DE LA LITERATURA Y DEL LENGUAJE
}

\author{
Francisco Abad
}

(UNED, Madrid)

\section{CHARLES SANDERS PEIRCE}

La historia de la estética entra en un momento nuevo en una fecha que podemos situar hacia 1740, año en que escribe David Hume y en torno al cual ha empezado a escribir ya nuestro Feijoo y lo van a hacer Diderot, Lessing, etc.; contamos pues con una larga duración de unos dos siglos y medio que el estudioso ha de atender cuando se haga cargo de la historia de las ideas estéticas y de la teoría de la literatura, y en esa duración aparece como nombre señero el de Charles Sanders Peirce. Vamos a atender nosotros a algunos de sus textos, y a la vez a la presencia de Peirce en las teorizaciones de Roman Jakobson en cuanto un catalizador fecundante de ellas; Peirce según decimos es nombre señero, y a pesar de la dificultad de sus textos debe quedar reseñado en esa historia literalmente fascinadora de la estética y la teoría literaria desde hacia 1740 hasta -por poner una fecha- 1990, año en el que desaparece Dámaso Alonso. 
De 1952 es un texto jakobsoniano que pocas veces hemos visto destacado, pero que tenemos por fundamental en su trayectoria y revelador en la trayectoria toda del estructuralismo: nos referimos a los «Resultados de una conferencia conjunta de antropólogos y lingüistas» (Jakobson 1988: 231-242; comp. Aranguren 1986: 37-43). Tal informe a esa Conferencia contiene por lo menos:

a) Una formulación ya explícita de qué es la «función poética» del lenguaje.

b) La idea de la variabilidad del idioma en la propia sincronía, y por tanto la de que el cambio es en sus inicios un hecho sincrónico.

c) La necesidad de abordar el análisis de las formas semánticas de contenido, o sea, el análisis de las «invariantes semánticas».

Ya hemos advertido que esta proclama nos parece relevante, y está pensada en términos que resultan anteriores a lo que suele creerse; sin embargo ahora nos importa por su referencia a Peirce. Charles S. Peirce había dicho en efecto: «Un signo o representamen es algo que representa algo para alguien... Se dirige a alguien, es decir, crea en la mente de esa persona un signo equivalente o quizás aún más desarrollado. A este signo creado yo lo llamo el Interpretante del primer signo» (1987: 144-245); lo que nos permite interpretar los signos linguiísticos es por tanto la tensión estructural interna que existe entre los mismos, las diferenciaciones entre ellos logradas merced a los rasgos pertinentes del contenido, y esto es lo que atrae a Jakobson. Jakobson se encuentra postulando un análisis estructural del vocabulario y ve en Peirce a «un precursor genuino y genial de la lingüística estructural», ya que Peirce al hablar de los signos «interpretantes» está operando con la idea de la invariación semántica y de los rasgos pertinentes de contenido que hacen que se configure el léxico y que el vocabulario posea rendimiento funcional.

Un signo de una semiótica puede ser traducido a otro signo de otra semiótica diferente: esta tarea interpretante se hace posible por la existencia de los rasgos de contenido, de los caracteres significtivos invariantes, según establece Peirce.

\section{EL CARÁCTER ICÓNICO DE LOS SÍMBOLOS}

Un escrito más centralmente dedicado al autor norteamericano es el que Jakobson elabora en 1965: «Charles Sanders Peirce y la búsqueda de 
la esencia de la lengua» (1988: 113 ss.), en el que recoge esta afirmación suya: «Soy... un pionero o mejor dicho un explorador, en la labor de desbrozar y abrir... la doctrina de la naturaleza esencial y las variedades fundamentales de la semiosis posible»; estamos en verdad ante un análisis de la semiosis, esto es, de la 'operación productora de signos' o 'función semiótica' según definen Greimas y Courtès (1982: 364b), del proceso por el que un significante y un significado entran en relación «necesaria» entre sí y a la vez con otros significantes y otros significados.

En cuanto explorador de la semiosis Peirce ha establecido por ejemplo la mencionada noción de «interpretante», de un signo que creamos para interpretar otro en la misma semiótica o en una semiótica distinta; este proceso resulta posible porque la semiosis se establece a partir de unas formas de la expresión vinculadas con formas del contenido no menos estructuralmente establecidas -desde luego bien establecidas en la semiótica del lenguaje - (cfr. por ej. Pottier 1977: 61 ss.; Katz y Fodor 1976).

Se ha recordado que Charles S. Peirce propuso en una ocasión que hay 59.049 tipos de signos; desde luego resulta fundamental la tricotomía que distingue los «iconos», los «índices» y los «símbolos», clases que nuestro autor delimitaba de esta manera:

\footnotetext{
Un icono es un signo que remite al objeto que él denota, meramente por virtud de caracteres propios y que posee por igual tanto si tal objeto existe o no... Cualquier cosa... es un icono de algo en la medida en que es como esa cosa y es empleado como un signo de ella...

Un índice es un signo que se refiere al objeto que denota en virtud de que es realmente afectado por ese objeto... En la medida en que el índice es afectado por el objeto tiene necesariamente alguna cualidad en común con el objeto y es por respecto a ella como se refiere al objeto...

Un símbolo es un signo que se refiere al objeto que él denota por medio de una ley... Por consiguiente él mismo es un tipo general o ley, vale decir, es un legisigno (1987: 250; comp. Hierro 1980: 25-49).
}

Un plano de una casa es un icono en cuanto posee analogía con ella, y es icono aunque la tal casa aún no haya sido construida; el humo - ejemplo clásico- es índice del fuego que se está produciendo, y no hace falta que alguien vea ese humo para que sea índice; los símbolos obedecen al acuerdo o convención, y existen como tales en el seno de comunidades culturales que los tienen instituidos. Los símbolos (por ejemplo los llamados signos lingüísticos, las voces o palabras) han sido establecidos y consisten por tanto en «legisignos»; «un Legisigno —define Peirce- es una ley que es un signo. Esta ley es generalmente instituida por los hombres. Todo signo convencional es un legisigno» (1987: 249). 
Jakobson reproduce como es natural en su escrito de 1965 esta delimitación de clases de signos (1988: 114-115), y la reformula por su cuenta diciendo que el icono presenta semejanza de hecho entre el signans y el signatum, el índice una contigüidad existencial entre tales signans y signatum y el símbolo una contigüidad atribuida entre ellos y que ha habido que aprender; además Jakobson viene a decir que esta cuestión de la semejanza auténtica o de la arbitrariedad que se da respectivamente en los iconos y los símbolos quedó planteada y discutida ya en el Crátilo platónico.

Ciertamente Platón aborda el asunto en su Diálogo, y así hace decir primero a Hermógenes: «-Sócrates, aquí Cráfilo afirma que cada uno de los seres tiene el nombre exacto por naturaleza» (Platón 1983: 364); luego el mismo Hermógenes postula: «Pues bien Sócrates, yo... no soy capaz de creerme que la exactitud de un hombre sea otra cosa que pacto y consenso... Y es que no tiene cada uno su nombre por naturaleza alguna, sino por convención» (Platón 1983: 365-366). Los nombres significan pues o por naturaleza o por convención, y Sócrates mantendrá en este texto platónico que efectivamente lo hacen por lo segundo, que «resulta sin duda inevitable que tanto convención como costumbre colaboren a manifestar lo que pensamos cuando hablamos» (Platón 1983: 452),

$\mathrm{El}$ asunto de la motivación o la arbitrariedad en la constitución de los signos se encuentra en la historia del pensamiento lingüístico en el Crátilo platónico; el mismo problema es el que se le plantea a Peirce a la hora de establecer una de sus tricotomías de signos, y él atendiendo a lo que es natural y a lo que es por convención delimita iconos e índices por una parte, y símbolos por la otra.

Además Charles S. Peirce establece que los diagramas «representan las relaciones... de las partes de una cosa mediante relaciones análogas en sus propias partes» (1987: 263); los diagramas poseen por tanto naturaleza icónica, y así «de hecho cualquier ecuación algebraica es un icono, en la medida en que exhibe por medio de signos algebraicos... las relaciones de las cantidades en cuestión» (1987: 265). Jakobson ahonda en estos pensamientos de Peirce, y enuncia y ejemplifica:

Tanto en sintaxis como en morfología cualquier relación de las partes y los todos
concuerda con la definición de Peirce de los diagramas y su naturaleza icónica...
En las distintas lenguas indoeuropeas los grados positivo, comparativo y superlati-
vo del adjetivo muestran un aumento gradual en el número de los fonemas... El
singnans del plural tiende a reflejar con una dimensión acrecentada de la forma el
significado de un incremento numérico (1988: 119).

Además de su carácter arbitrario, las lenguas humanas están penetradas de un carácter icónico que es el que ha subrayado Jakobson siguien- 
do la traza de Peirce; asimismo ocurre que «un símbolo puede poseer un icono y/o un índice incorporado en sí mismo», y a esto hay que atender (Jakobson 1988: 123).

En efecto Roman Jakobson estima que «los constituyentes icónicos y de índice de los símbolos verbales» han quedado preteridos en muchas ocasiones, pero que sin embargo suponen "perspectivas de gran alcance» para la ciencia filológica (1988: 123); él no lo dice, pero es evidente que el ámbito en el que el lenguaje tiende a hacerse icónico es el de la literatura.

Las bellas letras consisten en discursos que muchas veces poseen un cierto carácter icónico o contienen elementos de iconicidad; la obra en cuanto signo global o signo literario puede tener una cierta forma icónica, o poseer significantes icónicos (lo que se ha llamado «fonología expresiva»), etc. Por ejemplo los sonetos manieristas en los que se ha visto una disposición en la que el tema principal está preterido como señal de sabiduría técnica en la composición, efectivamente significan con su disposición el contenido 'maestría técnica', y ello les da un carácter icónico.

El significante ya hemos dicho que se hace icónico en lo que se conoce como fonología expresiva: algunos fonemas sugieren un determinado contenido si aparecen acumulados en un decurso que asimismo por sus significados sugiere el mismo contenido. Un ejemplo bien conocido es el que analizó Dámaso Alonso: en los versos de Garcilaso

En el silencio sólo se escuchaba un susurro de abejas que sonaba,

«el elemento de silencio está expresado por medio de fricativas, ante todo de las eses (silencio, sólo, se escuchaba, susurro, abejas, sonaba), y el punto de vahariento zumbido dentro del paisaje silencioso, por la única erre cuyo efecto ya se propaga a toda la voz susurro» (Alonso 1989: 64).

Por nuestra parte también creemos que se da un caso de fonología expresiva en el «Solo del Pastor Bobo» de El público de Lorca: la sustancia significada de 'lo podrido', 'lo muerto', la sugiere la propia descomposición de un lenguaje repetitivo, cacofónico y ripioso:

El pastor bobo guarda las caretas, las caretas

de los pordioseros y de los poetas, que matan a las gipaetas

cuando vuelan por las aguas quietas. 


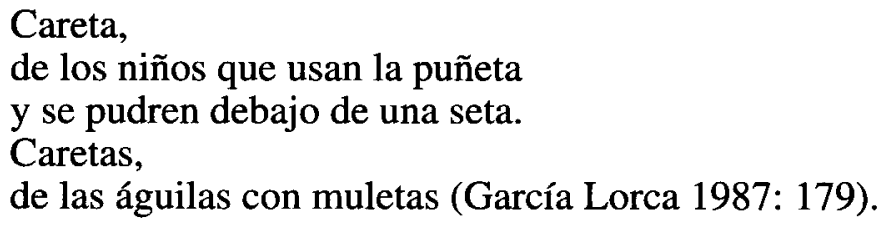

Según decimos nos parece que existe una correspondencia icónica entre el contenido connotado de 'lo quieto', lo 'muerto', y el cierto sinsentido en que precipita el discurso por sus repeticiones de fonemas y su carácter ripioso.

La literatura y también la lengua ordinaria pueden poseer algo de iconicidad, y esto es lo que Jakobson argumenta o simplemente insinúa en la traza de Peirce: se trata de una perspectiva que según hemos visto le parece «de gran alcance» y por tanto inauguradora de «tareas nuevas y urgentes» (1988: 123).

\section{LA TAREA DEL HÉROE}

En fin Peirce es tenido en cuenta en las páginas que en 1974 dedica Jakobson a una «Ojeada sobre el desarrollo de la semiótica» (1988: 350353 ), y en otras posteriores (del año 1977) en que vuelve a «Algunas precisiones en torno a Peirce, pionero de la lingüística» (1988: 125-130). En este momento advierte nuestro autor cómo la vida de Peirce resultó desafortunada y cómo «la falta de un entorno agradable» frenó el desarrollo de sus actividades científicas; por lo demás Jakobson vuelve a insistir en la fértil diferenciación entre iconos, índices y símbolos, y en que -en palabras literales de Peirce- «los signos más perfectos son aquellos en que los caracteres icónicos, indicadores y simbólicos se funden» (1988: 130). La literatura puede encontrarse penetrada - en una u otra medida - de carácter icónico, y aparece así como un signo «más perfecto».

Por supuesto en otras ocasiones el nombre y las ideas de Charles Sanders Peirce aparecen en los escritos jakobsonianos; nosotros nos hemos referido a algunas de esas ideas, y a su huella en Roman Jakobson. En particular Peirce ha constituido un estímulo para que Jakobson percibiese la necesidad de encarar el análisis componencial del contenido, la configuración pertinente que poseen las piezas léxicas del idioma y en general sus formas de contenido; por otra parte a Jakobson no se le ha escapado lo que de icónico posee el idioma y también - aunque no lo diga en los textos ahora considerados de manera explícita - la literatu- 
ra: las formas lingüísticas y asimismo las obras poéticas pueden estar constituidas por un componente de iconicidad que el estudioso debe conocer.

\section{CONCLUSIONES}

Los párrafos presentes han expuesto algunas ideas que ahora recogemos en abreviatura:

1. La Estética moderna se constituye hacia mitad del Setecientos, cuando Hume, Feijoo, Diderot, etc., escriben de ella; en esta historia de las ideas estéticas y de la teoría de la literatura que se extiende desde hace unos dos siglos y medio hasta nuestros días, y además en la historia de las ideas linguíísticas, cabe un lugar que no puede quedar desatendido a Charles Sanders Peirce. Peirce fue un adelantado o "pionero» - como dice Jakobson- de la ciencia del lenguaje (cf. Plazaola 1991: 85-278).

2. Peirce introduce el concepto de «interpretante» para designar con él a un signo que equivale a otro signo en la misma o en distinta semiótica; tales signos que «parafrasean» a otros signos se fundamentan - podemos decir- en los rasgos pertinentes del contenido que dan lugar a unos y a otros.

3. Peirce distinguió según bien se sabe «iconos» de «índices»y de «símbolos». Los «iconos» poseen alguna(s) analogía(s) con el objeto al que se refieren, y no necesitan que ese objeto exista realmente o no.

4. Los «índices» suponen una contigüidad existencial entre su signans y su signatum: la mancha de humedad en la pared es índice de una fuga de agua.

5. Los símbolos suponen una convención establecida entre signans y signatum: los llamados «signos» lingüísticos son símbolos en este sentido, y se dan como tales en una comunidad hablante que los sanciona con su uso.

6. Peirce discurre en esta tripartición de los signos de acuerdo con el problema que ya quedó planteado en el Crátilo platónico: ¿los nombres significan «por naturaleza» o «por convención»? En el Crátilo tanto 
Hermógenes como Sócrates se pronuncian por la segunda de las dos opciones.

7. Peirce llama «diagrama» a una 'representación de las relaciones de las partes de una cosa mediante relaciones análogas en sus propias partes'; los diagramas son pues icónicos.

8. Cualquier enunciado algebraico es un icono, y lo mismo el lenguaje posee rasgos icónicos, hecho particularmente subrayado por Jakobson.

9. Las obras literarias pueden dar lugar cada una a un signo icónico; el discurso literario puede estar construido en efecto de tal manera que posea cierta iconicidad respecto de lo que se quiere decir.

10. Un caso de iconicidad en el discurso poético es el de la fonología expresiva. En definitiva ocurre que la (buena) literatura constituye un caso de signo más perfecto, ya que al «símbolo» del lenguaje en que está escrita se suma lo que de icónica pueda tener.

Charles Sanders Peirce es un autor complejo cuyo estudio no compete sólo a los filólogos sino a los lógicos, filósofos, etc.; desde una sensibilidad filológica suelen destacarse algunas de sus afirmaciones, y a ellas nos hemos referido nosotros aquí. Su intuición de lo arbitrario del lenguaje, de la posible iconicidad que no obstante puede poseer, de la red de tensiones sistemáticas que individualizan y a la vez organizan a las palabras entre sí, constituye un hallazgo seguro de pionero que se adelantó y que - por ello y en justicia - reclama nuestro cálido recuerdo.*

\section{Referencias bibliográficas}

Alonso, D. (1989): Obras Completas, IX. Madrid: Gredos.

ARANGUREN, J. L. (1986): La comunicación humana. Madrid: Tecnos.

García LorCa, F. (1987): El público. María Clementa Millán (ed.). Madrid: Cátedra.

GREIMAS, A. J.-CouRTES, J. (1982): Semiótica. Diccionario razonado de la teoría del lenguaje. Madrid: Gredos.

HIERRo, J. (1980): Principios de Filosofia del lenguaje. I. Madrid: Alianza.

\footnotetext{
* Agradecemos a nuestros compañeros Alicia Yllera y José Romera su amable acogida de nuestro trabajo en el Seminario, y a ellos dos y a M. A. Garrido la participación que tuvieron en el coloquio que siguió a la abreviatura oral de estas páginas.
} 
JAKOBSON, R. (1988): Obras Selectas. I. Madrid: Gredos.

KATZ, J. J.-FodOR, J. A. (1976): La estructura de una teoría semántica. México: Siglo $\mathrm{XXI}$.

Peirce, Ch. S. (1987): Obra lógico-semiótica. Armando Sercovich (ed.). Madrid: Taurus.

Platón (1983): Diálogos. II, Julio Calonge y otros autores (eds.). Madrid: Gredos.

Plazaola, J. (1991): Introducción a la Estética. Bilbao: Universidad de Deusto.

POTTIER, B. (1977): Lingüística general. Madrid: Gredos.

En sentido amplio léase TRÍAS, E. (1970): Metodología del pensamiento mágico, Barcelona: Edhasa, 49-86. 